\title{
WAVELENGTH DISCRIMINATION BY THE GOLDFISH NEAR ABSOLUTE VISUAL THRESHOLD
}

\author{
Maureen K. Powers 1.2 \\ Department of Psychology. University of Michigan. Ann Arbor, MI 48109, U.S.A. \\ and \\ STEPHEN S. EASTER JR \\ Department of Experimental Biology. Division of Biological Sciences. University of Michigan, \\ Ann Arbor, MI 48109. U.S.A.
}

(Received 21 October 1977)

\begin{abstract}
Goldfish were classically conditioned to discriminate between $532 \mathrm{~nm}$ and $636 \mathrm{~nm}$ lights while light adapted, and then tested for their ability to continue the discrimination as the intensities were reduced. In all tests, the two stimuli were balanced for effectiveness at absolute threshold. We find that goldfish can discriminate between these wavelengths about $1 \log$ unit above absolute threshold. In contrast, fish who were trained to discriminate between $532 \mathrm{~nm}$ and $441 \mathrm{~nm}$ stopped discriminating $2-3 \log$ units above absolute threshoid. There are two conclusions from these results. First. some aspect of the neural signals generated by the rod and red cone mechanisms must be different. despite electrophysiological evidence that suggests they are the same. Second, the goldfish has color vision near rod threshold.
\end{abstract}

Key Words-goldfish; rod-cone interactions; color discrimination; respiratory conditioning; scotopic vision: retina.

\section{INTRODUCTION}

A single visual receptor cannot tell the wavelength of quanta that influence it. Color vision-the ability to distinguish wavelengths independent of their intensities-requires at least two receptor mechanisms with different spectral sensitivities. In goldfish, two spectrally different receptor mechanisms-probably rods and red cones-mediate absolute threshold (Powers and Easter, 1978); therefore this animal has the potential for color vision at very low intensities.

Although color vision cannot occur unless there are two kinds of receptor, their existence does not guarantee it. Neural activity beyond the receptors must maintain the distinctions between them. Evidence suggests that the messages from the goldfish's rods and red cones share similar anatomical and physiological channels to the ganglion cells, and thus do not remain separate at higher levels of processing. Rods and red cones affect ganglion cell responses similarly (Raynauld, 1969, 1972; Adams and Afanador, 1971; Beauchamp and Daw, 1972), and they may use common bipolar cell pathways to the ganglion cells (Scholes and Morris, 1973; Scholes, 1975; Stell, 1976). Because the ganglion cell axons form the optic nerve, which is the only exit from the retina. these studies suggest that the goldfish should not have color

\footnotetext{
'Submitted in partial fulfilment of the requirements for the degree Doctor of Philosophy in Psychology, at the University of Michigan.

2 Cument address: Maureen K. Powers, Department of Psychology NI-25, University of Washington, Seattle. Washington 98195 , U.S.A.
}

vision near absolute threshold, despite the presence of two receptor mechanisms.

The similarity between rod and red cone signals suggested to us that a conditioned response to rod stimulation should generalize easily when red cones are stimulated, and vice versa. Our early experiments were designed to test this hypothesis.

Our initial test for generalization between rod and red cone signals yielded encouraging results. Darkadapted goldfish which were trained to slow their heart rate when they detected an increment of $532 \mathrm{~nm}$ light near absolute threshold generalized more strongly to an increment of $636 \mathrm{~nm}$ light than to an increment of $532 \mathrm{~nm}$ light during light-adapted tests (Powers and Easter, 1975). When we attempted to replicate and expand these findings, however, we met with little success. Extensive testing showed that while generalization was almost always in the predicted direction, it was not strong and only rarely attained statistical significance (Powers, 1977). These results led us to consider a complementary hypothesis: that the neural messages from rods and red cones are suffciently different to allow the fish to discriminate between them. This paper describes a test of that hypothesis.

In the experiments reported here, light-adapted goldfish were classically conditioned to discriminate between red and green lights. Then the intensities (of both stimuli) were reduced until the fish no longer discriminated between the two wavelengths. Some of the same fish were trained to discriminate between blue and green, and tested in the same way. The results show that. close to absolute threshold, the goldfish can discriminate long from medium wavelengths but not short from medium. 


\section{METHFOOS}

\section{Apparatus}

The apparatus was the same as described in Powers and Easter (1978), with the following two exceptions: (1) only one channel of the optical stimulator was used: (2) stimulus and shock presentation were controlled by hand

Srimuli

Calibration procedures were described previously (Powers and Easter, 1978). All stimuli in this study were 132 in diameter. and were presented on a dark field. During light-adapted training sessions stimulus intensity was 6-8 log units above absolute threshold (Powers and Easter. 1978). and will hereafter be referred to as "photopic." The intensities of all stimulus pairs were adjusted to produce equal visual effectiveness. according to the appropriate spectral sensitivity curve (light-adapted: Powers. 1978: dark-adapted: Powers and Easter. 1978). Interference and neutral density filters (Optics Technology) set wavelength and intensity of the stimuli. The half bandwidths of the interference filters were $25-55 \mathrm{~nm}$.

\section{Subjects}

Twenty-one goldfish (Carassius auratus. Ozark Fisheries. Stoutland. MO) $13-15 \mathrm{~cm}$ tip-to-tip. were subjects in this study. They were dark adapted in their home aquaria for at least $40 \mathrm{~min}$ before sessions at low intensities. and were put into the test box $10-15 \mathrm{~min}$ before training or testing began.

\section{Training procedure}

Although the experiments reported here used a discrimination paradigm, many of the training procedures were similar to those used in the detection paradigm described earlier (Powers and Easter. 1978): the reader is referred to that paper for details omitted here.

All fish were given preliminary habituation sessions during which no stimulus was presented. Then they were exposed for at least one session (20 trials) to the stimulus that was not to be paired with shock - the nondiscriminative stimulus (NDS). The stimulus that was paired with shock - the discriminative stimulus (DS)-was introduced in the next session. This session was considered to be the first training session.

There were 5 DS trials and 15 or 16 NDS trials in a discrimination training session. The order of presentation was random except that DS trials were never consecutive and there were never more than 4 consecutive NDS trials.

The response criterion for single trials was the same as described in Powers and Easter (1978): respiration rate had to decrease to half its usual rate. The percent of trials that evoked a criterion response was calculated for the DS and for the NDS for each fish following each session. The quantity (percent response to DS minus percent response to NDS) will be called $\Delta R$. and is an indicator of the discriminability of the two lights. An animal was considered trained when $\Delta R \geq 60$ for two consecutive sessions.

Testing procedures are described in the Results section.

\section{RESULTS}

\section{Photopic discrimination training}

Three wavelength pairs were used: $441 \mathrm{~nm} / 532 \mathrm{~nm}$ $472 \mathrm{~nm} / 532 \mathrm{~nm}$ and $636 \mathrm{~nm} / 532 \mathrm{~nm}$. The first discrimination attempted was $472 \mathrm{~nm} / 532 \mathrm{~nm}$. Four fish were subjects; for two the DS was $532 \mathrm{~nm}$ and for the other two it was $472 \mathrm{~nm}$. Despite lengthy training.

${ }^{3}$ One had since died. none of the fish performed at our criterion level: their final $\Delta R$ 's were $-7,3,12$ and 33

A group of ten fish, also counterbalanced for wavelength of DS. was then trained to discriminate between $636 \mathrm{~nm}$ and $532 \mathrm{~nm}$. We will tefer to this as the red/green discrimination. Seven of them learned in an average of about six sessions. This success rate $\left(70^{\circ}\right)$ is comparable to that for a detection task (Powers and Easter. 1978). Cising yet another group of subjects, we tried to condition the same red, green discrimination when the intensity of each wavelength was randomly varied $\pm 0.5 \mathrm{log}$ units around photopic equivalence; varying the intensity was an attempt to increase the probability that the fish were discriminating on the basis of wavelength alone. This task was apparently more diffictil for the fish. because only two out of the seven subjects learned it in an average of ten sessions.

After the nine fish who learned the red/green discrimination had been tested (see below) eight of them ${ }^{3}$ were trained to discriminate between $441 \mathrm{~nm}$
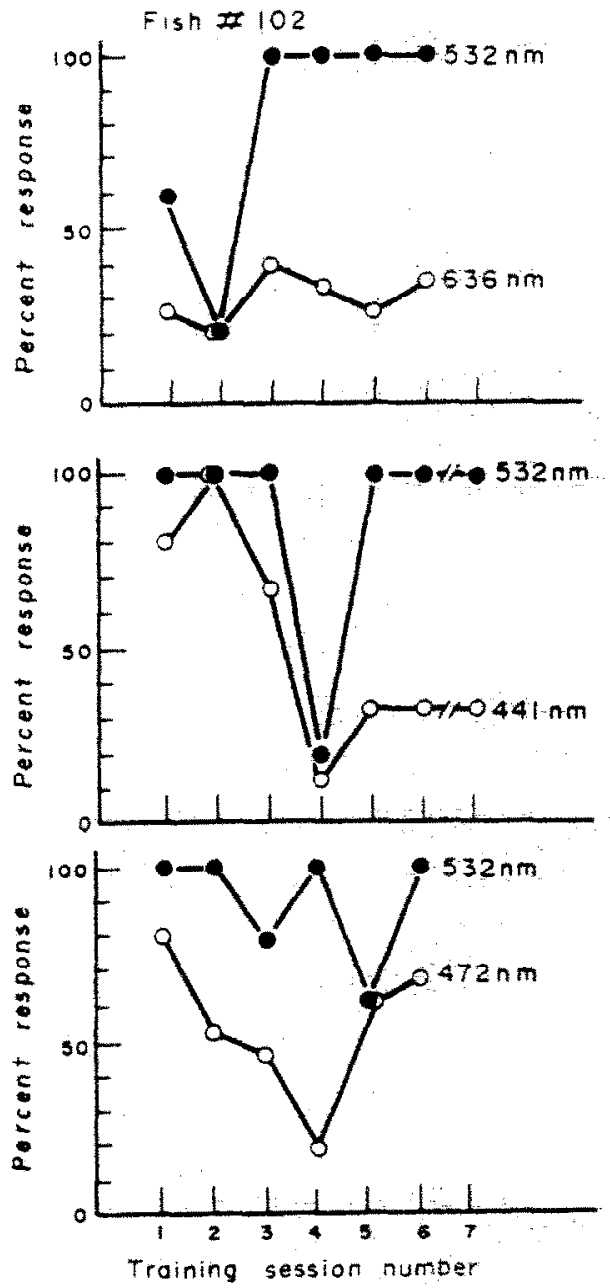

Fig. 1. Discrimination learning curves for one lightadapted fish (No. 102). Ordinate: percent of trials during which response criterion was met. Filled circles: stimulus associated with shock (DS). Open circles stimulus not associated with shock (NDS). $532 \mathrm{~nm}$ was always DS for this fish. There were 7 days between sessions 6 and 7 for $532 \mathrm{~nm} / 441 \mathrm{~nm}$ training; session 7 was 1 day after the last $\$ 32 \mathrm{~nm} / 472 \mathrm{~nm}$ sesston 
Table 1. Photopic wavelength discrimination

\begin{tabular}{lccccc}
\hline & \multicolumn{4}{c}{ Between $532 \mathrm{~nm}$ and: } \\
& $441 \mathrm{~nm}$ & $472 \mathrm{~nm}$ & $636 \mathrm{~nm}$ & $\begin{array}{c}636 \mathrm{~nm} \\
\text { variable } \\
\text { intensity }\end{array}$ \\
\hline $\begin{array}{c}\text { Percent success } \\
\text { Mean sessions to } \\
\text { criterion } \\
\text { (learners) }\end{array}$ & 63 & 0 & 70 & 29 \\
$\begin{array}{c}\text { Mean sessions } \\
\text { (nonlearners) }\end{array}$ & 5.7 & 8.6 & 6.7 & 8.4 \\
Total $v$ & $3^{\circ}$ & $5^{*}$ & 10 & 7 \\
\hline
\end{tabular}

* Percent of subjects who performed at criterion levels.

${ }^{6}$ All eight had previously learned to discriminate $636 \mathrm{~nm}$ from $532 \mathrm{~nm}$.

' One fish had previously learned to discriminate both $636 \mathrm{~nm}$ and $441 \mathrm{~nm}$ from $532 \mathrm{~nm}$.

and $532 \mathrm{~nm}$. We will refer to this as the blue/green discrimination. For each fish, the response to green during blue/green retraining was the same as it had been during red green training. That is, if green was DS for a given fish in the red/green discrimination. it remained $D S$ in the blue/green discrimination. Five of the eight fish learned the blue/green discrimination in an average of four sessions each.

Finally, one of the most reliable fish (No. 102) was again retrained. this time on the original $472 \mathrm{~nm} /$ $532 \mathrm{~nm}$ discrimination. The fish did not meet criterion within six sessions, despite its extensive experience. The learning curves for No. 102 are in Fig. I.

Table 1 summarizes the results of photopic discrimination.

\section{Discrimination testing}

Subjects who had learned red/green or blue/green discriminations while light adapted were tested for

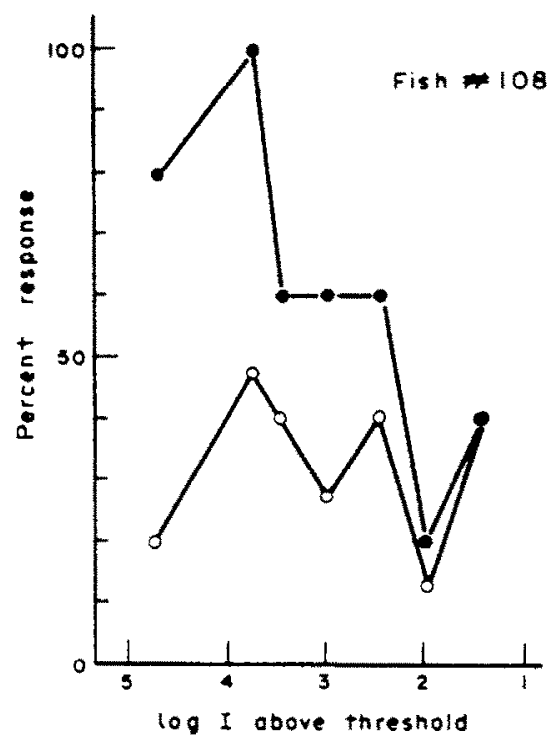

Fig. 2. Breakdown of a discrimination at low intensities in one subject (No. 108). Ordinate: Same as Fig. 1. Abscissa: $\log$ intensity of the test stimuli, relative to absolute threshold. Filled circles: DS (532 nm). Open circles: NDS $(636 \mathrm{~nm})$. Stimuli were balanced for equal dark-adapted effectiveness. Each pair of points at a given intensity is from one session on one day. their ability to discriminate between the same wave. lengths at progressively lower intensities. The test was a modified staircase psychophysical procedure. Each day an animal was tested for its response to the conditioned wavelength pair. but at an intensity 0.5 or 1.0 log units less than on the previous day. The procedure for any given session was the same as the lightadapted training these fish had already received: there were 20-21 trials day, and reinforcement followed all DS presentations. $\Delta R$ was calculated for each session and any positive value during testing was taken to imply discrimination, however weak. When $\Delta R$ reached zero, testing was terminated.

Figure 2 shows the performance of one subject during such a series of daily tests. As the intensity decreased. $\Delta R$ gradually diminished, but it stayed positive until between 1 and $2 \log$ units above absolute threshold (Powers and Easter. 1978). Note that when $\Delta R$ reached zero, the fish still responded to individual stimuli. This argues against the possibility that the basic light-shock association was extinguished at the end of testing.

Functions like the one in Fig. 2 were obtained for five other animals trained to discriminate between red and green, and for four of the same fish trained to discriminate between blue and green. $\Delta R$ was calculated as described earlier at each intensity tested. The values of $\Delta R$ for all individual subjects are shown in Fig. 3. For clarity, the mean $\Delta R$ of all subjects tested at a given intensity with a given wavelength pair is plotted separately in Fig. 4. The results show that the ability to discriminate between blue and green is lost before the ability to discriminate between red and green. This was true of all individual subjects. Furthermore, the ranges of individual values of $\Delta R=0$ did not overlap between the blue/green and red/green discriminations. $\Delta R$ was zero at 0.80 $( \pm 0.45$ S.D.) $\log$ units above absolute threshold for

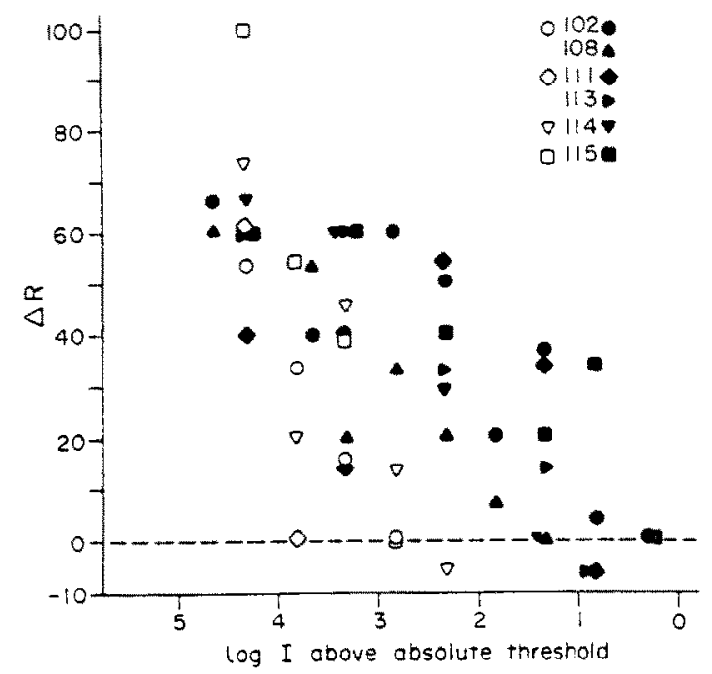

Fig. 3. Wavelength discrimination at low intensities. Ordinate: difference in percent response (percent response to DS minus percent response to NDS). Absicissa: intensity of the stimuli, relative to absolute threshold. for the balanced pair. Open symbols: blue/green discrimination. Closed symbols: red/green discrimination. $N=6$ for red/ green and 4 for blue/green. Red: $636 \mathrm{~nm}$; green: $532 \mathrm{~nm}$ : blue: $441 \mathrm{~nm}$. Multiple points at a single location have been plotted with slight horizontal displacement. 


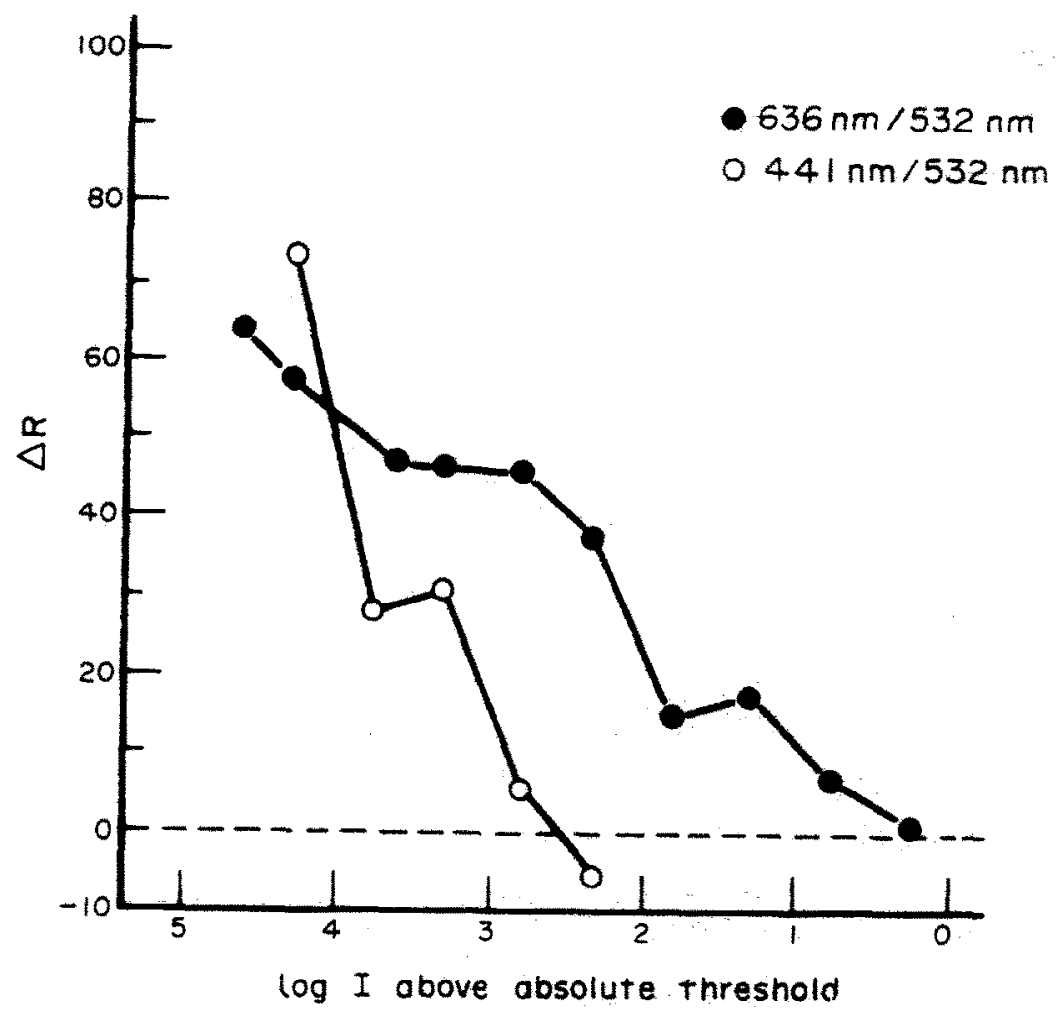

Fig. 4. Mean values for discrimination of wavelength at low intensities. Axes and data same as Fig. 3. Filled symbols: means for the red/green discrimination; open symbols: means for the blue/green discrimination.

the red/green discrimination and $2.98( \pm 0.63$ S.D. $) \log$ units above absolute threshold for the blue/green discrimination.

In order to ascertain whether the discrimination was based on wavelength or intensity, five red/green discrimination subjects were retested at $1 \log$ unit above the intensity where $\Delta R$ was zero for each of them. The intensities of the red and green lights were varied $\pm 0.5 \log$ units randomly from trial to trial. The data from Training Session No. 1 in Fig. 5 show the results of this test. The animals could discriminate between the two lights even when intensity was varied; a comparison of mean $\Delta R$ from this session with mean $\Delta R$ for the same subjects when intensity was constant shows a difference of less than $5 \%$ These results indicate that the discrimination was not made on the basis of intensity.

Finally, we tried to improve performance at $1 \mathrm{log}$ unit above the intensity where red/green discrimination ceased for each fish by repeating the procedure just described for four more sessions. As Fig. 5 shows, the training did not help.

\section{DISCussion}

\section{Light-adapted wavelength discrimination}

The results of the photopic discrimination training support earlier reports (McCleary and Bernstein, 1959; Muntz and Cronly-Dillon, 1966; Yager, 1967; Shefner and Levine, 1976) that the goldfish has photopic color vision, and that blue/green discrimination is more difficult than red/green (Muntz and CronlyDillon, 1966). The fish in our study which learned the $441 \mathrm{~nm} / 532 \mathrm{~nm}$ discrimination were all highly ex- perienced, having previously been trained on the red/ green task. When naive, our fish did not learn the $472 \mathrm{~nm} / 532 \mathrm{~nm}$ discrimination at all. Even the most reliable experienced fish (No. 102, see Fig I) did not learn the task. The electrophysiology of retinal ganglion cells suggests a basis for the diffieulty: blue and green receptors have similar effects on ganglion cells

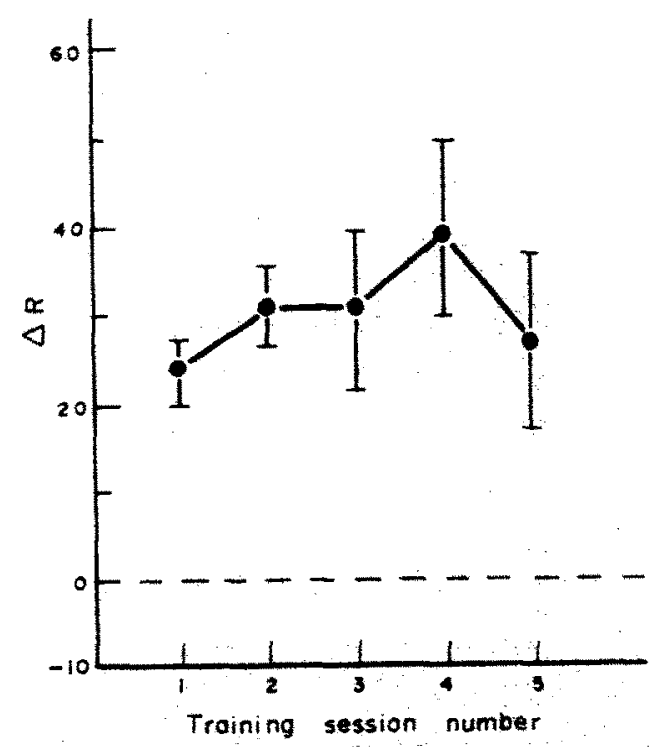

Fig. S. Repetitive testing near the intensity where the red/ green discrimination is no longer possible. The inteasity of the test light was randomly varied within a $\pm 0.5 \mathrm{log}$ unit range of equal dark-adapted effectiveness. Mean scores for five fish; bars \pm I S.EM 
(Beauchamp and Lovasik, 1973), while red and green receptors have opposite effects (Wagner, MacNichol and Wolbarsht. 1963; Daw, 1968).

\section{Dark-adapted wavelength discrimination}

The goldfish can no longer discriminate between medium and short wavelengths when the intensity of the light is about $3 \log$ units above absolute threshold. Several lines of evidence suggests that this value is approximately what would be expected if rods alone were responsible for catching quanta at low intensities in this region of the spectrum. First, Yager (1968) found 3 log units difference in sensitivity between the peaks of the behavioral dark- and lightadapted action spectra he measured in goldfish. This suggests that mid-spectral lights exceeding absolute threshold by about $3 \log$ units will stimulate cones. Second. Raynauld (1969) reported seeing cone-dominated activity in goldfish retinal ganglion cells $2.5 \mathrm{log}$ units above absolute threshold when he stimulated with green light. Third, we have shown (Powers and Easter. 1978) that photomechanical movement of the cones toward their light-adapted positions occurs at about $3 \log$ units above absolute threshold; this finding is consistent with the more quantitative analy. sis made by Easter and Macy (1978) in another teleost. And fourth, the rod/cone break for mid-spectral wavelengths in peripheral retina is at a comparable location in human subjects (Stiles, 1939). The inability to discriminate between short and medium wavelength lights equated for dark-adapted effectiveness means the rods are probably the only photo receptors functioning at these wavelengths.

The ability to discriminate between medium and long wavelengths, on the other hand, does not break down until their intensities are very close to absolute threshold. Therefore, the goldfish has color vision in the longer-wavelength portion of the spectrum at intensities near the limit of seeing. This conclusion is strengthened by our earlier demonstrations (Powers and Easter, 1978) that (1) more than one visual pigment absorption spectrum is needed to match the spectral sensitivity at absolute threshold, and (2) the long wavelength portion of the threshold spectral sensitivity curve can be adapted without reducing the peak sensitivity.

If the two mechanisms are rods and red cones, as seems likely, then there is no obvious reason for the inability to continue discriminating at absolute threshold. A clue may come from human psychophysics, where a small interval between absolute threshold and threshold for color exists even for very long wavelengths (Bouman and Walraven, 1957; Graham and Hsia. 1969). Although the achromatic interval may not occur under all experimental circumstances (see discussion in Marriott, 1976), we have observed it, using ourselves as subjects, under conditions similar to those of our goldifish: long, large flashes of $703 \mathrm{~nm}$ in the peripheral retina (see Powers, 1977). If flashes at threshold (or slightly above) that affect red cones do not always appear colored, and flashes that affect rods also are not colored, then the goldfish's inability to tell them apart at threshold is understandable.

Finally, we turn to an attempt to reconcile our finding that the goldfish can discriminate wavelengths using its rods and red cones with the fact that the messages these two receptors send to ganglion cells are similar (Raynauld, 1969: 1972; Adams and Afanador. 1972; Beauchamp and Daw, 1972). We treat this problem in two ways. First we argue that it is advantageous to this animal to have rods and red cones affect the ganglion cells similarly; and second, we suggest that the signals might differ in a subtle way as yet unobserved by electrophysiologists.

Current theories of underwater visibility (Lythgoe. 1968. 1975; Easter. 1975) contend that contrast is highest at those wavelengths where the underwater space light is least (i.e. in the long wavelengths). If only the rods were active at low levels of illumination. the band of detectable wavelengths would be narrow. excluding much of the longer wavelength. higher contrast light. We have shown, however, that the goldfish is more sensitive to long wavelength lights while dark adapted than would be possible if only its rods were active (Powers and Easter, 1978). We would argue that this extra sensitivity to long wavelength light serves to increase the width of the spectral window in a manner that favors contrast detection. If contrast is an important feature in the fish's environment, then having the ganglion cells respond in a similar way regardless of which receptor is stimulated would be advantageous; the fish could gain information from a wide spectral range without unnecessary concern about wavelength.

Despite the apparent ecological advantages of and the actual electrophysiological evidence for similarity between rod and red cone initiated signals in ganglion cells, we have shown that they cannot be identical because goldfish can discriminate between them. Raynauld's $(1969,1972)$ original finding. upon which our early generalization experiments were based (Powers and Easter, 1975), was that the quality of input from rods and red cones to ganglion cells was the same: if the cell was excited by rod input, it was also excited by red cone input. We suggest that the discrimination reported here results from quantitative differences in the signals from rods and red cones, perhaps in the time-course of a ganglion cell's discharge produced by each (cf. Gouras and Link, 1966. in monkey retina). Such differences are almost certainly small (because $\Delta R$ was small, and could not be improved, close to threshold), and thus could easily have been overlooked in earlier electrophysiological studies.

To summarize, we believe that the behavior and electrophysiology are not inconsistent with one another. Rods and red cones affect the ganglion cells similarly, but probably not identically, and we suggest that the small differences can be used by the animal to discriminate wavelengths. Although we have suggested that the time course of the ganglion cell discharge could be the difference in question, this remains to be demonstrated.

Acknowledgements-Supported by PHS grant EY-00168 to S.S.E., and by graduate student research grants from the Department of Psychology and the Graduate School, University of Michigan, to M.K.P. M.K.P. was supported by predoctoral fellowships from the Graduate School and from NIMH. We thank M. Alpern for helpful comments on an earlier draft. 


\section{REFEREXCES}

Adams A. J. and Afanador A. J. (1971) Ganglion cell receptive field organization at different levels of light adaptation. Am. J. Optom. 48, 889-896.

Beauchamp R. D. and Daw N. W. (1972) Rod and cone input to single goldfish optic nerve fibers. Vision Res. 12. $120 \mid-1212$.

Beauchamp R. D. and Lovasik J. V. (1973) Blue mechanism response of single goldfish optic fibers. J. Neurophysiol. 36. 925-939.

Bouman M. A. and Walraven P. L. (1957) Some color naming experiments for red and green monochromatic lights. J. opt. Soc. Am. 47, 834-839.

Daw N. W. (1968) Colour-coded ganglion cells in the goldfish retina: Extension of their receptive felds by means of new stimuli. $J$. Physiol 197. 567-592.

Easter S. S. Ir (1975) Retinal specialisations for aquatic vision: Theory and facts. In Vision in Fishes (edited by Ali M. A.). Plenum Press. New York.

Easter S. S. Jr and Macy A. (1978) Local control of retinomotor activity in the fish retina. Vision Res. 18, 937-942.

Gouras P. and Link K. (1966) Rod and cone interaction in dark adapted monkey ganglion cells. $J$. Physiol. 184. 499-510.

Graham C. H. and Hsia Y. (1969) Saturation and the foveal achromatic interval. J. opt. Soc. Am. 59. 993-997.

Lythgoe I. N. (1968) Visual pigments and visual range underwater. Vision Res. 7.997-1011.

Lythgoe J. N. (1975) Problems of seeing colours under water. In Vision in Fishes (edited by Ali M. A.). Plenum Press. New York.

Marriott F. H. C. (1976) Other phenomena. In The Eye V. 2A (edited by Davson H.) Academic Press. New York.

McCleary R. A. and Bernstein J. J. (1959) A unique method for the control of brightness cues in study of color vision in fish. Physiol. Zool. 32. 284-292.

Muntz W. R. A. and Cronly-Dillon J. R. (1966) Colour discrimination in goldfish. Anim. Behat. 14, 351-355.
Powers M. K. (1977) Visual sensitivity of the goldfist. Ph.D. dissertation. Liniversity of Michigan.

Powers M. K. (1978) Light-adapted spectral sensitivity of the goldtish: A reflex measure 18. This issue pp. $1131-1136$

Powers M. K. and Easter S. S. It (1975) A behayoural test of rod-red cone convergence in the goldfish retina. In Vision in Fishes fedited by Ali M. A.). Plenum Press. New York.

Powers M K and Easter S S. It (19.8) Absolute visual sensitivity of the goldfish. Vision $R$ z 18 . This isste pp. $1137-1147$

Raynauld J. P. (1969) Rod and cone responses of ganglion cells in goldfish retina: A microelectrode study. Ph- D: dissertation. Johns Hopkins Universicy.

Raynauld J. P. (1972) Goldfish retina Sign of the rod input in opponent color ganglion cells. Stence $177.34-85$.

Scholes J. H. (1975) Colour receptors, and their syraptic connexions, in the retina of cyprinid fish: Phil Trans: R. Soc. B 270. $61-118$.

Scholes J. H. and Morris J. (1973) Receptor-bipolar connectivity patterns in fish retina. Narure 241, 52-54.

Shefner J. M. and Levine M. W. (1976) A psychophysical demonstration of goldfish trichromacy. Vision Res. 16 . $671-673$

Stell W. K. (1976) Functional polatization of horizontal cell dendrites in goldfish retina: 1 nest. Ophthahnot. 15. $895-908$.

Stiles W. S. (1939) The directional senstivity of the retina and the spectral sensitivities of the rods and cones. Proc. R. Soc. B 127, 61-105.

Wagner H. G., MacNichol E. F. Ir and Wolbarsht M. L. (1963) Functional basis for "on"-center and "of -center receptive fields in the retina. J. opt. Soc. Am. 53. 66-70.

Yager D. (1967) Behavioral measures and theoretical analysis of spectral sensitivity and spectral saturation in the goldfish. Carassius auratus. Vision Res. $7,707-727$.

Yager D. (1968) Behavioural measures of the spectral sen. sitivity of the dark-adapted goldfish. Nafure 220 . $1052-1053$. 